\title{
A choice experiment study on the fuel preference of Kibera slum households in Kenya
}

\author{
A. Yonemitsu ${ }^{1}$, M. Njenga ${ }^{2}$, M Iiyama $^{2} \&$ S. Matsushita ${ }^{3}$ \\ ${ }^{I}$ Graduate School of Life and Environmental Sciences, \\ University of Tsukuba, Japan \\ ${ }^{2}$ World Agroforestry Centre (ICRAF), Kenya \\ ${ }^{3}$ Faculty of Life and Environmental Sciences, \\ University of Tsukuba, Japan
}

\begin{abstract}
In Kenya, woody biomass, especially the charcoal derived from it, is an important energy resource for cooking. As better energy alternatives become available and affordable in developing countries, households tend to switch from traditional biomass to modern fuels such as liquid petroleum gas, kerosene, and electricity. This fuel-switching pattern is often called the 'energy ladder', the ladder steps representing upgrades in the quality of energy services. Meanwhile, fuel briquettes recycled from charcoal dust are gaining popularity as an alternate fuel in urban households facing problems of waste management. The valuing of energy services is important for policy planning and for improving the socioeconomic conditions and environments of households. The objective of this study is to assess the current energy use status of the urban poor in Kenya. More specifically, the study aims to better understand the relative importance of fuel substitution, especially with regard to charcoal, fuel briquettes, and kerosene, and the factors associated with their choice. To estimate the product-specific factors, we conducted a choice experiment study of households in the Kibera slums of Nairobi, Kenya, by applying a conditional logit model to identify the various socioeconomic characteristics that determine household preferences for cooking fuels. The study revealed household preferences for modern energy sources and several characteristics affecting consumer choice.
\end{abstract}

Keywords: charcoal, charcoal briquettes, fuel consumption, biomass energy, urban poor, Kenya. 


\section{Introduction}

Woody biomass, especially charcoal, is an important energy source in Kenya. Urban households in informal settlements rely almost entirely on charcoal for their basic cooking energy needs [1-4]. Charcoal is preferred because it produces less smoke, its calorific value is twice that of wood, and it lasts longer, especially when used with improved cooking stoves. Moreover, charcoal is considered affordable, economical, and convenient and has an extensive distribution network that ensures its availability in informal settlements. Thus, charcoal is one of the options of cooking fuels for many poor residents. A previous study showed that the world production of charcoal in 2004 was 1.6 million tons [4]. Population increases and urbanization have led to the increased demand for charcoal in sub-Saharan Africa (SSA). This trend, coupled with the inefficient charcoal production and consumption technologies and households' inaccessibility to other modern energy sources, is not likely to change in the near future [5].

Charcoal production is considered the major cause of deforestation, mostly on account of unsustainable harvesting and inefficient production techniques $[6,7]$. For instance, only $10-20 \%$ of the raw wood is converted to charcoal during the production process because of the use of inefficient kilns. Further, about $10-15 \%$ of charcoal is wasted along the supply chain to form dust or fines from breakages during handling; this dust can be mainly found at the retail and wholesale stalls [8]. Faced with the disposal challenges of charcoal dust, slum communities turn to making charcoal briquettes with the dust recovered from among the other organic by-products. The dust has considerable energy value and can be recycled into fuel briquettes. In Kenya, the use of fuel briquettes is spreading among the urban and rural households and there is a huge potential for briquettes to become an affordable and good cooking fuel. Charcoal briquettes have been found to be environmentally beneficial since they produce less smoke, increase the total cooking energy by more than $15 \%$, and thereby save an equivalent volume of trees that would otherwise be cut down for charcoal [9].

Substituting charcoal with electricity and/or liquid petroleum gas (LPG) should be one of the remedies to reduce the pressures of deforestation and health risks from indoor pollution [1]. With regard to the relationship between household economic growth and energy consumption, some empirical and micro-level studies have presented the 'energy ladder' hypothesis, which states that an increase in income helps households shift their energy sources from traditional biomass to modern fuels [10-12]. However, differing with the energy ladder hypothesis, there is an argument that households in developing countries do not switch to modern energy sources but rather tend to consume a combination of fuels [13, 14]. A study on Ethiopia has shown that households do not switch completely from biomass to modern fuels, but rather increase the number of fuels used as their total expenditure rises $[15,16]$. We consider it crucial to understand the factors that affect the consumption patterns of cooking energy, that is, the substitution and diversification of energy sources, of the lower-income urban households in SSA, rather than simply assuming the energy ladder hypothesis. We need a more policy-relevant and realistic theory of household energy demand, because the 
benefit of policies that ignore fuel stacking may be less than hypothesized. In fact, only a few studies have seriously examined the multiple fuel use in SSA. The causes of fuel stacking in Kenya are also not well understood, although we know that increases in population, economic growth, and urbanization have led to an increasing energy demand in Kenya. Therefore, we need to analyse the transition from charcoal to kerosene, which is the most important modern energy option for the poor in Nairobi, and the adoption of charcoal briquette as a substitute/complement to charcoal.

The primary aim of this study is to better understand the relative importance of fuel substitution and fuel complementation, especially with regard to charcoal, fuel briquettes, and kerosene. More specifically, we analyse the determinants of the fuel preferences of urban poor households. For this, we use a choice experiment based on a stated preference survey of slum dwellers of Nairobi and a conditional logit (CL) model.

\section{Methodology and approach}

\subsection{Study sites and approach}

We conduct our study in Nairobi, Kenya, located $1^{\circ} 00^{\prime \prime} \mathrm{N}$ and $30^{\circ} 00^{\prime \prime} \mathrm{E}$ in southern Kenya at an elevation of $1670 \mathrm{~m}$ above sea level and covering an area of 700 square kilometres. We estimate the city's population at three million, with an annual growth rate of $2.8 \%$ between 2000 and 2015 , constituting $7.5 \%$ of the country's population [8]. Sixty per cent of the city's population live in low-income informal settlements, and the urban poor is projected to increase to $65 \%$ by 2015 [17]. These settlements comprise one of the most densely populated informal settlements in the world and Africa's largest slum. The exact number of people living in this slum area is not clear, as the 1999 census showed the figure close to one million whereas the 2009 census figure stood at 0.4 million within an area of 2.5 square kilometres. Owing to the high density of the settlements, unplanned residential areas, and crowded houses, as well as the lack of infrastructure, the settlements' acute problems of drainage, sanitation, and solid waste management have been worsening continuously. The fuel use and demand patterns of Kibera's households largely depend on their end uses such as cooking and lighting, as well as the energy uses of home-based commercial and productive activities in small micro-enterprises (SMEs) [18].

We conducted a household survey in the Gatwekera and Kisumu villages in the Kibera slums during December 2011. The households in the villages are able to choose briquettes as an energy option because of the presence of briquette production sites or retail shops in the region. We selected 25 households randomly along four footpaths in each village and interviewed a total of 200 villagers. The households were selected by picking every fifth one on each footpath located within a radius of $250 \mathrm{~m}$ from the market street. 


\subsection{Choice experiment design}

We employed the orthogonal main-effects design in this study; this design is effective in terms of isolating the effects of individual attributes on a choice. The ability to incorporate orthogonality into the CE design is an important advantage over revealed preference random utility models.

Table 1 shows the attributes, namely, the price and distance to buy, expressed quantitatively for varying levels. As the table shows, the choices offered to respondents include three labelled ones and the 'neither' option. If neither of the fuel profiles was found satisfactory, the respondent could identify neither as the 'do not buy option'. We assigned four levels to the price attributes in each choice: the ranges of levels were estimated based on market information gathered from our pilot survey conducted in August 2011.

Using the orthogonal main-effects design with $R$ statistics software, our final design consisted of 24 choice sets. However, since the 24 sets were too large for each respondent to answer, we randomly divided the sets into four subsets of six choice sets each. We then randomly allotted the respondents interviewed to subsets A, B, C, or D, and by completing a subset, each respondent had to select a preferred option from the four possible choices in the six choice sets. Table 2 shows an example of a choice set actually used in the questionnaire.

Table 1: Allocation of levels and labels for the two attributes.

\begin{tabular}{llll}
\hline & Briquettes & Charcoal & Kerosene \\
\hline Price (Ksh) & $\{1,2,3,4\}$ per 1 block & $\{15,25,35,45\}$ per 2 kg & $\{80,90,100,110\}$ per litre \\
Distance (minute) & $\{15,30\}$ minutes walk & $\{15,30\}$ minutes walk & $\{15,30\}$ minutes walk \\
\hline
\end{tabular}

Table 2: Example of choice set from the household survey in Kibera.

\begin{tabular}{lllll}
\hline & Briquettes & Charcoal & Kerosene & NEITHER \\
\hline Price & Ksh.1 /block & Ksh.25/2kg tin & Ksh.110/liter & \\
Distance & 15 minutes & 30 minutes & 30 minutes & \\
\hline
\end{tabular}

\subsection{Model specification}

We used the random utility model in this study to explain individual choices by specifying the functions of the utility derived from the available alternatives. This function can be estimated by using the CL model. The indirect utility function of individual $n$ who chooses alternative $i$ in the choice set can be expressed as

$$
U_{\text {in }}=V_{\text {in }}+\varepsilon_{\text {in }} .
$$

This utility function, $U_{i n}$, can be decomposed into a deterministic part, $V_{i n}$, and a stochastic part, $e_{i n}$. Furthermore, if $U_{i n}>U_{j n}$ for all $i \neq j$ in the choice set $\mathrm{C}$, the probability that individual $n$ will choose alternative $i$ can be given by

$$
P_{i n}=P\left\{V_{i n}+\varepsilon_{i n}>V_{j n}+\varepsilon_{j n} ; \text { for all } j \epsilon C(i \neq j)\right\} .
$$


The probability of individual $n$ selecting alternative $i$ from choice set $C_{n}$ in the CL model can be shown as follows:

$$
P(i)=\exp \left(V_{i n}\right) / \sum_{j \epsilon C_{n}} \exp \left(V_{j n}\right) .
$$

$V_{\text {in }}$ is a systematic component of utility usually assumed to be a linear additive function of the independent variables $X_{i k}$ with coefficients $\beta_{i k}$ :

$$
V_{i n}=\sum_{k=1}^{K} \beta_{i k} X_{i k} .
$$

In order to test the effect of the relevant individual characteristics on choice, we introduce socioeconomic variables into Eq (4). This model can be expressed as

$$
V_{i n}=\sum_{k=1}^{K} \beta_{i k} X_{i k}+\sum_{k=1}^{K} \sum_{h=1}^{H} \gamma_{k h} X_{i k} S_{h n} .
$$

In the CL model, the marginal willingness to pay (MWTP) for a non-monetary variable is calculated as $b_{n m} / b_{m}$, where, $b_{n m}$ is the estimated coefficient of the non-monetary variable and $b_{m}$ the estimated coefficient of a monetary variable. Further, the confidence intervals for the MWTP are frequently calculated by using a simulation method based on a vector of means and the variance-covariance matrix of estimates developed by Krinsky and Robb [19].

\section{Results and discussions}

\subsection{Descriptive analysis}

We conducted a total of 200 person-to-person interviews, from which 187 were valid for further examination. The socioeconomic conditions of these 187 surveyed households (13 responses were invalid) are presented in Table 3 . The average size of a slum household was 4.67 persons and average age of the household head 34 years. Most of the household heads were male; female-headed households accounted for only $15.5 \%$ of all households. The average number of children below the age of 14 was 1.2 . The average household income was 151,288 $\mathrm{Ksh} / \mathrm{year}$, which is far below the poverty line of 1.25 USD a day.

\subsection{Estimation results}

The CL model estimation results are presented in Table 4. The coefficients on all the attributes in the main-effects model are statistically significant at the $1-5 \%$ levels. The variable BRI has significantly negative coefficients, indicating that the respondents evaluated briquettes lower than charcoal. In contrast, the coefficient of variable KERO is significantly positive, indicating that the respondents valued kerosene higher than charcoal. The coefficient for the PRICE attribute is negative and statistically significant. The higher the price, the lower is the probability that a respondent will select the alternative. 
Table 3: Socioeconomic conditions of surveyed households.

\begin{tabular}{|c|c|c|c|c|}
\hline & Mean & Std. dev. & Min. & Max. \\
\hline Sample size & 187 & & & \\
\hline \multicolumn{5}{|l|}{ Household size and composition } \\
\hline Household size (persons) & 4.67 & 1.76 & 2 & 10 \\
\hline Female-headed households (\%) & 15.51 & & & \\
\hline Household head age (years) & 34.65 & 9.52 & 20 & 69 \\
\hline Education level of household head (years) & 9.82 & 2.62 & 2 & 19 \\
\hline Children below 5 years of age (person) & 0.96 & 0.86 & 0 & 5 \\
\hline Children aged between $5-14$ years (person) & 1.19 & 1.24 & 0 & 6 \\
\hline \multicolumn{5}{|l|}{ Income source (\%) } \\
\hline Regular salaried & 28.90 & & & \\
\hline Casual labouring & 54.00 & & & \\
\hline SME & 50.80 & & & \\
\hline Annual Income (Ksh) & 151,288 & 155,660 & 6,000 & $1,056,000$ \\
\hline
\end{tabular}

Source: Household survey conducted by the authors in 2010 .

Table 4: Estimation results of conditional logit model.

\begin{tabular}{|c|c|c|c|c|}
\hline & \multirow{2}{*}{ Explanatory variables } & \multirow{2}{*}{ Main effects } & \multicolumn{2}{|c|}{ Cross effects } \\
\hline & & & Female-headed HH & Annual income \\
\hline \multirow[t]{2}{*}{ BRI } & dummy variable & $-1.06 \mathrm{E}+00$ & $5.51 \mathrm{E}-01$ & $-1.09 \mathrm{E}-06$ \\
\hline & (Briquettes=1) & $(0.024) * * *$ & $(0.004)^{* * *}$ & $(0.042)^{* *}$ \\
\hline \multirow[t]{2}{*}{ KERO } & dummy variable & $1.95 \mathrm{E}+00$ & $-6.45 \mathrm{E}-01$ & 7.27E-07 \\
\hline & $($ Kerosene $=1)$ & $(0.000) * * *$ & $(0.026)^{* *}$ & $(0.014)^{* *}$ \\
\hline \multirow[t]{2}{*}{ DIST } & walking time to retail shop & $-3.96 \mathrm{E}-02$ & $-1.17 \mathrm{E}-02$ & 7.72E-09 \\
\hline & & $(0.000) * * *$ & $(0.403)$ & $(0.758)$ \\
\hline \multirow[t]{2}{*}{ PRICE } & price per $\mathrm{MJ}$ & $-1.45 \mathrm{E}+00$ & & \\
\hline & & $(0.000)^{* * *}$ & & \\
\hline $\mathrm{L}(0)$ & -1232.643 & & & \\
\hline $\mathrm{L}(\beta)$ & -1029.236 & & & \\
\hline$\rho^{2}$ & 0.1650168 & & & \\
\hline$a d_{j} \cdot p^{i}$ & 0.1569041 & & & \\
\hline
\end{tabular}

Next, the coefficient estimates for all cross effects except for the interaction between DIST and socioeconomic demographic variables in the cross effect model are also statistically significant at the $1 \%$ or $5 \%$ level. Moreover, their signs of annual income are consistent with our expectation. The cross effect between kerosene and annual household income is positive. This means that as the level of household income increases, the probability of households choosing kerosene over charcoal also increases. In contrast, the coefficient for the cross effect of briquette and annual income is negative and statistically significant. This result also shows the effect of household heads' gender on the choice of briquettes and kerosene. From the signs of the coefficients, we find that female-headed households prefer briquettes to charcoal. 
Table 5: Marginal willingness to pay (MWTP) estimates and confidence intervals.

\begin{tabular}{|c|c|c|c|}
\hline \multirow{2}{*}{ Attributes } & \multicolumn{3}{|c|}{ MWTP per household } \\
\hline & \multicolumn{2}{|l|}{ Estimates } & $95 \%$ confidence itervals \\
\hline \multicolumn{4}{|l|}{ Main effects } \\
\hline Briquettes (unit: 1MJ) & Ksh. $\quad-0.735$ & $* * *$ & Ksh. -0.966 to -0.566 \\
\hline Kerosene (unit: $1 \mathrm{MJ}$ ) & 1.347 & $* * *$ & Ksh. 1.045 to 1.545 \\
\hline Distance (unit: 1minute) & Ksh. $\quad-0.027$ & $* * *$ & Ksh. -0.041 to -0.018 \\
\hline \multicolumn{4}{|l|}{ Cross effects } \\
\hline \multicolumn{4}{|c|}{ Female-headed household (yes=1) } \\
\hline Briquettes (unit: 1MJ) & 0.381 & $* * *$ & Ksh. 0.120 to \\
\hline Kerosene (unit: $1 \mathrm{MJ}$ ) & Ksh. -0.446 & $* *$ & Ksh. -0.877 to -0.061 \\
\hline Distance (unit: 1minute) & Ksh. -0.008 & & Ksh. -0.028 to \\
\hline \multicolumn{4}{|c|}{ Annual income (unit: 10,000) } \\
\hline Briquettes (unit: $1 \mathrm{MJ}$ ) & Ksh. -0.008 & $* *$ & Ksh. -0.016 to \\
\hline Kerosene (unit: $1 \mathrm{MJ}$ ) & 0.005 & $* *$ & Ksh. 0.001 to \\
\hline Distance (unit: 1minute) & 0.000 & & Ksh. 0.000 to \\
\hline
\end{tabular}

\subsection{Choice probability simulation of charcoal briquette}

Figure 1 shows a choice probability curve for charcoal briquette when the price of kerosene is fixed at the average retail price (Ksh. 2.48/MJ) [20]. We assigned the average values, 14.2 minutes and 15.3 minutes, for the DIST variables for briquette and kerosene, respectively. The walking time (DIST) to get briquettes and kerosene were calculated from the information gathered from our pilot study conducted in August 2011. We used the parameter estimates shown in Table 4 to simulate choice probability. As expected, the choice probability for briquettes increased as the price declined. However, the choice probability for briquettes was quite small and remained less than $5 \%$ at the maximum. We simulated the price competitiveness of briquettes among the three fuel types by using the CL model results (Table 4). More specifically, we estimated the price level, which makes the choice probability of choosing briquettes relatively equal to that of choosing kerosene priced at the average retail price of Ksh. 2.48 (/MJ). In other words, the utility of that alternative is equal to the utility of kerosene. In order to simulate the behaviour of the average household in our sample, we introduce an observed value into each socioeconomic variable. Therefore, a male-headed household with an income of Ksh. 151,288 per year can be considered an average household in the study area. As a result, we estimated the price of briquettes as $0.22 \mathrm{Ksh} / \mathrm{MJ}$. This value is close to the actual measured price. 


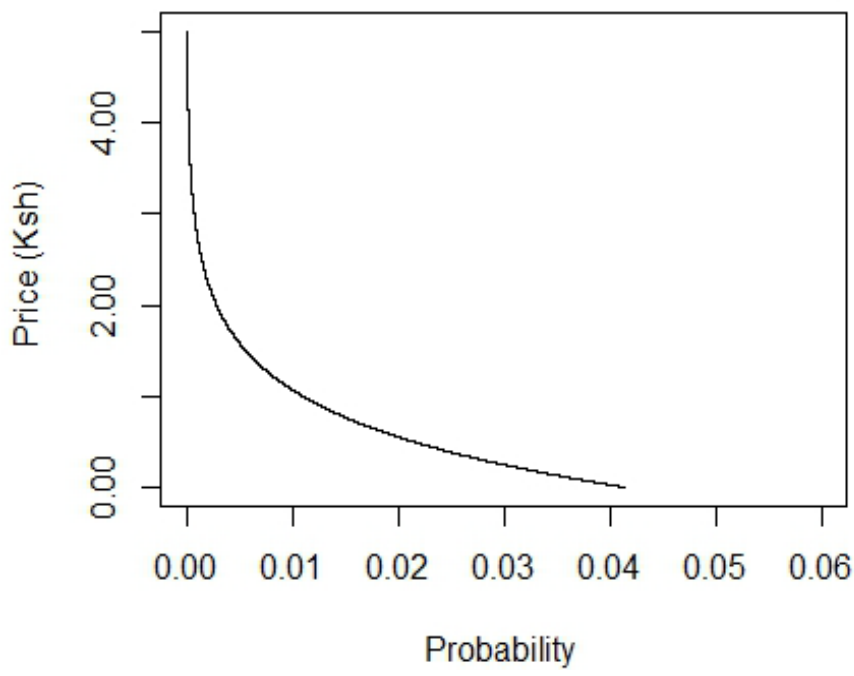

Figure 1: Choice probability curve of charcoal briquette.

\section{Conclusion}

In this study, we combined a choice experiment using a stated preference survey on the Kibera slums and a CL model to estimate the product-specific and socioeconomic factors influencing fuel choice.

The model results showed that households evaluate briquettes lower than charcoal but place a higher value for kerosene than for charcoal. In the cross effect model, the household heads' gender and household income affect the choice of fuels and their MWTP. The results were broadly consistent with the energy ladder theory, by which consumers or households tend to choose a modern energy source as their wealth increases.

From this survey, the mean MWTP estimations for the CL model with socioeconomic variable influences suggest that female-headed households as well as lower-income households prefer charcoal briquettes. In contrast, the households with higher income would be disinclined to choose briquettes. As the results have shown, households currently do not have a strong relative preference for charcoal briquettes over charcoal and kerosene. For those not yet using charcoal briquettes, however, the promotion of its use at the community level can help strengthen their motivation to adopt the fuel on account of its advantages such as low price, longer burning time, and less smoke. That is, the lack of information with regard to access to each energy source might constrain the ability to estimate the energy choice behaviour of households throughout the Kibera slums. Bioenergy and waste management initiatives should promote the recovery of organic by-products for the production of charcoal briquettes. 


\section{References}

[1] Karekezi S. Poverty and energy in Africa - A brief review. Energy Policy 30, pp. 915-919, 2002.

[2] Kenya Institute for Public Policy Research and Analysis (KIPRA), The Energy Regulatory Commission (ERC). A comprehensive study and analysis of energy consumption patterns in Kenya. Synopsis of the Draft Final Report, 2010.

[3] Mugo F, Ong C. Lessons of eastern Africa's unsustainable charcoal trade. ICRAF Working Paper 20, 2006.

[4] Mutimba S, Barasa M. National Charcoal Survey: Summary Report. Exploring the potential for a sustainable charcoal industry in Kenya. Energy for Sustainable Development Africa (ESDA), 2005.

[5] Maes WH, Verbist B. Increasing the sustainability of household cooking in developing countries: Policy implications. Renewable and Sustainable Energy Reviews 16, pp. 4204-4221, 2012.

[6] Chidumayo EN, Gumbo DJ. The environmental impacts of charcoal production in tropical ecosystems of the world: A synthesis. Energy for Sustainable Development 17, pp. 86-94, 2013.

[7] Mwampamba TH, Ghilardi A, Sander K, Chaix KJ. Dispelling common misconceptions to improve attitudes and policy outlook on charcoal in developing countries. Energy for Sustainable Development 17, pp. 75-85, 2013.

[8] Njenga M, Yonemitsu A, Karanja N, Iiyama M, Kithinji J, Sundberg C, Jarmnadass R. Implications of charcoal briquette produced by local communities on livelihoods and environment in Nairobi- Kenya. Int. Journal of Renewable Energy Development 2(1), pp. 19-29, 2013.

[9] Njenga M, Karanja N, Prain G, Malii J, Munyao P, Gathuru K, Mwasi B. Community-based energy Briquette production from urban organic waste at Kahawa Soweto Informal Settlement, Nairobi. Urban Harvest Working Paper Series Paper 5, 2009.

[10] Arnold M, Köhlin G., Persson R. Woodfuels, livelihoods, and policy interventions: Changing perspectives. World Development 34(3), pp. 596-611, 2006.

[11] Kojima M. The role of liquefied petroleum gas in reducing energy poverty. Oil, Gas, and Mining Policy Unit Working Paper. Extractive Industries for Development Series 25, 2011.

[12] Kebede B. Energy subsidies and costs in urban Ethiopia: The cases of kerosene and electricity. Renewable Energy, 2006.

[13] Brew-Hammond A, Kemausuor F. Energy for all in Africa — to be or not to be?! Current Opinion in Environmental Sustainability 1, pp. 83-88, 2009.

[14] Masera O, Saatkamp B, Kammen D. From linear fuel switching to multiple cooking strategies: A critique and alternative to the energy ladder model. World Development 28(12), pp. 2083-2103, 2000. 
[15] Mekonnen A, Köhlin G. Determinants of household fuel choice in major cities in Ethiopia. Environment for Development 36(8), pp. 2785-2790, 2008.

[16] Nansaior J, Patanothai A, Rambo AT, Simaraks S. Climbing the energy ladder or diversifying energy sources? The continuing importance of household use of biomass energy in urbanizing communities in Northeast Thailand. Biomass and Bioenergy 35, pp. 4180-4188, 2011.

[17] UN-Habitat, Nairobi urban sector profile. UN-Habitat Nairobi, 2006.

[18] Karekezi S, Kimani J, Onguru O. Energy access among the urban poor in Kenya. Energy for Sustainable Development 12(4), pp. 38-48, 2008.

[19] Krinsky I, Robb A. On approximating the statistical properties of elasticities. Rev Econ Stat 68, pp. 715-719. 1986.

[20] Timetric (https://timetric.com/). 